Original Article

\title{
Effects of aquatic PNF lower extremity patterns on balance and ADL of stroke patients
}

\author{
Eun-Kyung Kim, MSc1), Dong-Kyu Lee, MSc $\left.{ }^{2}\right)^{*}$, Young-Mi KIM, MSc ${ }^{1)}$ \\ 1) Department of Physical Therapy, Graduate School of Physical Therapy, Daegu University, Republic \\ of Korea \\ 2) Department of Physical Therapy, Yeol-Lin Hospital: 570-15 Songchung-Dong, Gwangsan-Gu, \\ Gwangju 504-704, Republic of Korea
}

\begin{abstract}
Purpose] This study investigated the effect of aquatic proprioceptive neuromuscular facilitation (PNF) patterns in the lower extremity on balance and activities of daily living (ADL) in stroke patients. [Subjects] Twenty poststroke participants were randomly assigned to an experimental group $(n=10)$ or a control group $(n=$ 10). The experimental group performed lower extremity patterns in an aquatic environment, and the control group performed lower extremity patterns on the ground. Both exercises were conducted for 30 minutes/day, 5 days/week for 6 weeks. Balance was measured with the Berg Balance Scale (BBS), Timed Up and Go Test (TUGT), Functional Reach Test (FRT), and One Leg Stand Test (OLST). Activities of daily living were measured with the Functional Independence Measure (FIM). A paired t-test was used to measure pre- and post-experiment differences, and an independent $t$-test was used to measure between-group differences. [Results] The experimental and control groups showed significant differences for all pre- and post-experiment variables. In the between-group comparison, the experimental group was significantly difference from the control group. [Conclusion] These results indicate that performing aquatic proprioceptive neuromuscular facilitation patterns in the lower extremity enhances balance and ADL in stroke patients.

Key words: Proprioceptive neuromuscular facilitation, Balance, Activities of daily living
\end{abstract}

(This article was submitted Jun. 19, 2014, and was accepted Aug. 3, 2014)

\section{INTRODUCTION}

Stroke is a neurological disease caused by the cutoff of normal blood supply due to vessel rupture or thrombosis, and it causes brain tissue damage. Motor, sense, recognition, language, and perception deficits are typical symptoms of the disease, depending on the affected areas, size, and the cause of damage ${ }^{1)}$. Stroke patients mainly experience motor disorders and degeneration of balancing ability due to unbalanced posture; this is caused by asymmetric arrangement and hemiplegia, and this disrupts independent activities of daily living (ADL) ${ }^{2}$.

The ability to balance is an individual's ability to maintain the center of gravity within a base region, keeping the body in a balanced state ${ }^{3)}$. Stroke patients lack balancing ability and show degeneration of physical function due to a reduction in walking and activity caused by an inappropriate posture, proprioception malfunction, and abnormal muscle tension ${ }^{4}$. To resolve balance problems caused by stroke, the Brunnstrom approach, Bobath approach, or pro-

*Corresponding author. Dong-Kyu Lee (E-mail: ldkpt@ hanmail.net)

(C2015 The Society of Physical Therapy Science. Published by IPEC Inc. This is an open-access article distributed under the terms of the Creative Commons Attribution Non-Commercial No Derivatives (by-ncnd) License $<$ http://creativecommons.org/licenses/by-nc-nd/3.0/> . prioceptive neuromuscular facilitation (PNF) is used; such methods focus on enhancing physical functions and balance by improving active motor control ${ }^{5)}$.

PNF utilizes a typical helical or diagonal pattern to stimulate proprioceptive sensation promote a nerve root response, enhancing functional movement ${ }^{5,6)}$. It improves muscle strength, flexibility, and balance; by applying it on the non-paretic side, force is transferred to the paretic side, effectively promoting muscle activity ${ }^{6}$.

Davis $^{7)}$ suggested aquatic PNF lower extremity patterns for reinforcing muscular strength and enhancing muscle reeducation. Song and $\mathrm{Kim}^{8)}$ applied aquatic PNF lower extremity patterns to patients who had a stroke, which stimulated proprioceptors, thus improving control and function of the nerve roots while enhancing balance.

In an aquatic environment, the buoyancy allows limbs to be moved more easily with little strength, enhancing coordination of motion ${ }^{9}$. Water resistance also enables the body to move, helping increase muscle strength, joint movement, and balance ${ }^{10)}$. Multiple studies had reported PNF lower extremity patterns during ground-based exercise for stroke patients, but few had reported aquatic PNF.

This study aimed to investigate the effects of aquatic PNF lower extremity patterns on balance and ADL of stroke patients. 


\section{SUBJECTS AND METHODS}

Six months after receiving a stroke diagnosis via either computed tomography or magnetic resonance imaging, 20 patients were randomly assigned to a control group $(\mathrm{n}=10$; 5 males and 5 females) or an experimental group ( $\mathrm{n}=10$; 5 males and 5 females); the control group was assigned to conduct PNF lower extremity patterns on the ground, and the experimental group was assigned to conduct PNF lower extremity patterns in water. All participants scored $>24$ points on the Mini-Mental Status Examination (MMSE), could perform assignments, were capable of walking $10 \mathrm{~m}$ independently, and were classified as $>4$ on the Brunnstrom scale. All participants were informed and provided informed consent before the experiment. The protocol was approved by the Institutional Review Board of Nambu University and was conducted in accordance with the ethical standards of the Declaration of Helsinki. The general features of the participants are listed in Table 1. The age of the experimental group was $69.1 \pm 3.2$ years, height was $167.6 \pm$ $8.2 \mathrm{~cm}$, weight was $67.9 \pm 5.9 \mathrm{~kg}$, and time since stroke onset was $9.8 \pm 1.3$ months. The age of the control group was $68.0 \pm 3.1$ years, height was $165.9 \pm 6.9 \mathrm{~cm}$, weight was 66.7 $\pm 6.7 \mathrm{~kg}$, and time since stroke onset was $10.3 \pm 1.4$ months.

The experimental group conducted PNF lower extremity patterns using the rhythmic initiation (RI) method $110 \mathrm{~cm}$ below the water surface; the water temperature was 31-33 ${ }^{\circ} \mathrm{C}$. Exercises were performed in a supine posture after simple stretching; subjects wore a body ring between $\mathrm{L}_{5}$ and $\mathrm{S}_{1}$ and a neck collar. The control group conducted PNF lower extremity patterns on the ground in a supine posture after simple stretching. The RI method starts from passive exercise, proceeds to active resistance exercise, and helps increase coordination, motor sensation, and balance. The PNF lower extremity patterns consisted of patterns $D_{1}$ and $D_{2}$. The $D_{1}$ pattern ends at either flexion-adduction-external rotation knee flexion or extension-adduction external rotation knee extension. The $\mathrm{D}_{2}$ pattern ends at either flexion-adduction external rotation knee flexion or extensionadduction-external rotation knee extension. PNF lower extremity patterns were conducted 30 minutes/day, 5 days/ week for 6 weeks.

Balance was measured with the Berg Balance Scale (BBS), Timed Up and Go Test (TUGT), Functional Reach Test (FRT), and One Leg Stand Test (OLST). The BBS consists of 14 items and can be categorized into sitting, standing, and postural changes. Scores in each category range from $0-4$, with 56 possible total points; higher scores indicate better balance. The TUGT measures the time required to stand up from a chair and shuttle back and forth between the chair and a spot in front of the subject three times. The FRT measures the distance one can reach with an arm from a standing posture. The OLST measures how long one can stand on one foot with the eyes open without placing the other foot on the ground.

ADL were measured with the Functional Independence Measure (FIM), which consists of 13 items related to mobility and 5 related to recognition. The items were scored on a scale of 1-7 with 126 possible total points; higher scores
Table 1. General characteristics of subjects

\begin{tabular}{lcc}
\hline & EG $(\mathrm{n}=10)$ & $\mathrm{CG}(\mathrm{n}=10)$ \\
\hline Gender (male/female) & $5 / 5$ & $5 / 5$ \\
Age (years) & $69.1 \pm 3.2^{\mathrm{a}}$ & $68.0 \pm 3.1$ \\
Height $(\mathrm{cm})$ & $167.6 \pm 8.2$ & $165.9 \pm 6.9$ \\
Weight $(\mathrm{kg})$ & $67.9 \pm 5.9$ & $66.7 \pm 6.7$ \\
Paretic side (right/left) & $5 / 5$ & $5 / 5$ \\
Onset (months) & $9.8 \pm 1.3$ & $10.3 \pm 1.4$ \\
\hline
\end{tabular}

${ }^{\mathrm{a}}$ Mean \pm SD, EG: experimental group, CG: control group

Table 2. Comparison of the results of the BBS, TUG, FRT, OLST, and FIM between the experimental and control groups

\begin{tabular}{lcccc}
\hline & Group & Pre & Post & D-value \\
\hline BBS & EG & $42.8 \pm 1.6^{\mathrm{a}}$ & $44.9 \pm 1.7^{*}$ & $2.1 \pm 1.7^{*}$ \\
& CG & $39.9 \pm 2.0$ & $40.6 \pm 1.7^{*}$ & $0.7 \pm 0.8$ \\
TUGT & EG & $21.9 \pm 1.3$ & $20.1 \pm 1.9^{*}$ & $-1.8 \pm 1.3^{*}$ \\
& CG & $20.4 \pm 1.0$ & $19.7 \pm 1.0^{*}$ & $-0.7 \pm 0.6$ \\
FRT & EG & $17.7 \pm 0.9$ & $19.0 \pm 1.4^{*}$ & $1.3 \pm 0.9^{*}$ \\
& CG & $16.7 \pm 0.6$ & $17.2 \pm 0.4^{*}$ & $0.5 \pm 0.6$ \\
OLST & EG & $4.3 \pm 0.8$ & $5.7 \pm 1.1^{*}$ & $1.4 \pm 0.9^{*}$ \\
& CG & $3.4 \pm 0.5$ & $4.1 \pm 0.7^{*}$ & $0.6 \pm 0.7$ \\
FIM & EG & $82.3 \pm 2.5$ & $87.5 \pm 3.7^{*}$ & $5.2 \pm 5.3^{*}$ \\
& CG & $80.1 \pm 1.2$ & $81.4 \pm 1.4^{*}$ & $1.3 \pm 1.3$ \\
\hline
\end{tabular}

${ }^{a}$ Mean \pm SD, ${ }^{*} \mathrm{p}<0.05$, D-value: difference value, EG: experimental group, CG: control group, BBS: Berg Balance Scale, TUGT: Timed Up and Go test, FRT: Functional Reach test, OLST: One Leg Stand test, FIM: functional independence measure

indicate better independence.

Data were analyzed using SPSS 12.0 (SPSS, Chicago, IL, USA) for Windows. Descriptive statistics were used for the general features of the participants. A paired t-test was used to determine pre- and post-experiment differences, and an independent t-test was used to determine between-group differences. Statistical significance was set at $\alpha=0.05$.

\section{RESULTS}

The changes in the result of the BBS, TUG, FRT, OLST, and FIM are listed in Table 2. The experimental and control groups showed significant differences for all pre- and postexperiment variables $(\mathrm{p}<0.05)$. In the between-group comparison, the experimental group was significantly different from the control group $(\mathrm{p}<0.05)$.

\section{DISCUSSION}

The purpose of this study was to investigate the effects of aquatic PNF lower extremity patterns on balance and ADL of stroke patients. The experimental group showed a significant improvement in balance and ADL after the aquatic PNF $(p<0.05)$ and had significantly better balance and ADL relative to the control group $(\mathrm{p}<0.05)$. This is consistent with previous studies. For example, perfor- 
mance of 10 weeks of aquatic proprioception exercise by seniors enhanced their motor abilities ${ }^{11)}$. In addition, Kim and Lee ${ }^{12)}$ PNF reported that aquatic lower extremity patterns enhanced balance in healthy adults. Moreover, Song and $\mathrm{Kim}^{8)}$ reported that aquatic PNF effectively affected the balance of stroke patients. These results indicate that aquatic PNF lower extremity patterns help enhance the balance of stroke patients. PNF, used as a gradual resistance exercise that employs a helical pattern, maximizes motor unit recruitment through proprioceptive stimulation ${ }^{5,13)}$. Aquatic PNF promotes the maximum usage of muscle fibers due to the intense circumstances caused by buoyancy and turbulence; moreover, the water acts as a form of resistance, stimulating proprioception and thus helping to improve postural control and balance ${ }^{8,13,14)}$.

The most common method for examining the ADL of stroke patients is to use the FIM. In the present study, the experimental group showed significant enhancement of ADL after the aquatic PNF $(p<0.05)$. Suomi and Collier $\left.{ }^{15}\right)$ reported that the ADL of arthritis patients were enhanced after conducting aquatic exercise, and Sato et al. ${ }^{16)}$ reported that the ADL of abnormal adults were enhanced after conducting water exercise. Similar to other studies, enhancement of ADL was observed after conducting aquatic exercise in the present study. The enhancement of ADL was the result of enabling movement with even a small amount of force. This was due to the assistance of the water buoyancy and decreased gravity, reducing the burden on muscles and joints ${ }^{10,15)}$. To promote functional recovery, the paretic side was spontaneously enabled, thus enhancing the ADL and improving functional independence ${ }^{15,16)}$. The movements also stimulate shortened muscles, promoting a training effect and enhancing $\mathrm{ADL}^{17}$.

A limitation of this study was that it utilized a small number of participants, and it was not confirmed that the positive effects persisted. Future research should address these things when investigating the effect of aquatic PNF lower extremity patterns in stroke patients.

\section{REFERENCES}

1) Feigin VL: Stroke epidemiology in the developing world. Lancet, 2005, 365: 2160-2161. [Medline] [CrossRef]
2) Lamb SE, Ferrucci L, Volapto S, et al. Women's Health and Aging Study: Risk factors for falling in home-dwelling older women with stroke: the Women's Health and Aging Study. Stroke, 2003, 34: 494-501. [Medline] [CrossRef]

3) Cohen H, Blatchly CA, Gombash LL: A study of the clinical test of sensory interaction and balance. Phys Ther, 1993, 73: 346-351, discussion 351-354. [Medline]

4) Michael KM, Allen JK, Macko RF: Reduced ambulatory activity after stroke: the role of balance, gait, and cardiovascular fitness. Arch Phys Med Rehabil, 2005, 86: 1552-1556. [Medline] [CrossRef]

5) Pollock A, Baer G, Langhorne P, et al.: Physiotherapy treatment approaches for the recovery of postural control and lower limb function following stroke: a systematic review. Clin Rehabil, 2007, 21: 395-410. [Medline] [CrossRef]

6) Klein DA, William JS, Wayne TP: PNF training and physical function in assisted-living older adults. J Aging Phys Act, 2002, 41: 476-488.

7) Davis BC: A technique of resistive exercise in the treatment pool. Physiotherapy, 1971, 57: 480-481. [Medline]

8) Song JM, Kim SM: The effect of aquatic exercise applied PNF patterns on body composition and balance performance in stroke patients. J Korean Proprioceptive Neuromuscul Facilitation Assoc, 2008, 6: 1-10.

9) Basmajian JV: Therapeutic exercise in the management of rheumatic diseases. J Rheumatol Suppl, 1987, 14: 22-25. [Medline]

10) McNeal RL: Aquatic therapy for patients with rheumatic disease. Rheum Dis Clin North Am, 1990, 16: 915-929. [Medline]

11) Devereux K, Robertson D, Briffa NK: Effects of a water-based program on women 65 years and over: a randomised controlled trial. Aust J Physiother, 2005, 51: 102-108. [Medline] [CrossRef]

12) Kim YN, Lee DK: Comparison between aquatic and ground environments of rhythmic initiation for postural control. J Phys Ther Sci, 2012, 24: 1269 1271. [CrossRef]

13) Kofotolis N, Kellis E: Effects of two 4-week proprioceptive neuromuscular facilitation programs on muscle endurance, flexibility, and functional performance in women with chronic low back pain. Phys Ther, 2006, 86: 1001-1012. [Medline]

14) Simmons V, Hansen PD: Effectiveness of water exercise on postural mobility in the well elderly: an experimental study on balance enhancement. J Gerotol A Biol Sci. Med Sci, 1996, 51: 233-238.

15) Suomi R, Collier D: Effects of arthritis exercise programs on functional fitness and perceived activities of daily living measures in older adults with arthritis. Arch Phys Med Rehabil, 2003, 84: 1589-1594. [Medline] [CrossRef]

16) Sato D, Kaneda K, Wakabayashi H, et al.: Comparison of 2-year effects of once and twice weekly water exercise on activities of daily living ability of community dwelling frail elderly. Arch Gerontol Geriatr, 2009, 49: 123-128. [Medline] [CrossRef]

17) Cassady SL, Neilsen DH: Cardio respiratory responses to calisthenics performed with upper and lower extremities on land and in water at given cadences. Phys Ther, 1992, 72: 532-538. [Medline] 